\title{
Effect of Prophylactic Ondansetron on the Incidence of Spinal Anesthesia-Induced Shivering and Hypotension in Elective Cesarean Sections:Double- Blind, Placebo-Controlled, Randomized Clinical Trial
}

Ahmad Salahat ( $\triangle$ Ahmad.salahatt@gmail.com )

An-Najah National University

Adham Abu Taha

An-Najah National University

Nouraldin Almasri

Rafidia Governmental Hospital

Essa Sweity

An-Najah National University

\section{Research Article}

Keywords: rophylactic Ondansetron, Spinal Anesthesia, Shivering, Hypotension , Elective Cesarean

Posted Date: May 26th, 2021

DOl: https://doi.org/10.21203/rs.3.rs-498935/v1

License: (c) (1) This work is licensed under a Creative Commons Attribution 4.0 International License.

Read Full License 


\section{BMC Anesthesiology}

\section{Effect of prophylactic ondansetron on the incidence of spinal}

2 anesthesia-induced shivering and hypotension in elective cesarean

3 sections: double-blind, placebo-controlled, randomized clinical

4 trial

5 Ahmad M Salahat ${ }^{1,}$ Adham Abu Taha ${ }^{2,}$ Nouraldin Almasri ${ }^{3}$ and Essa Sweity ${ }^{4}$

$6 \quad{ }^{1}$ Certified Registered Nurse Anaesthetist (CRNA), An-Najah National University, Nablus-

7 Palestine, postal code 9992200.

$8{ }^{2}$ Associate professor of pharmacology, Faculty of Medicine and Health Sciences, An-Najah

9 National University, Nablus- Palestine, postal code 9992200.

103 Anaesthesiologist doctor, Rafidia governmental hospital, Ministry of Health, Nablus-

11 Palestine, postal code 9992200.

$12{ }^{4}$ Critical Care Nurse (CCN), An-Najah National University, Nablus- Palestine, postal code 139992200.

$14 *$ Corresponding author: Ahmad M Salahat ${ }^{1}$ Ahmad.salahatt@gmail.com

Abstract

Background: Spinal anesthesia is the preferred method of anesthesia for caesarean section; however, it is associated with dangerous adverse effects on both mother and fetus, this includes: spinal anesthesia induced shivering and hypotension. Previous studies suggest serotonin may have a role in hypotension, bradycardia, and shivering occurrence perioeratively. In this prospective double-blind randomized control trial study, we evaluated the efficacy of the ondansetron, a serotonin receptor antagonist, on the incidence of spinal anesthesia-induced shivering, hypotension, nausea, vomiting and other possible complications in elective caesarean sections. This study conducted in Palestine, West Bank, Nablus city in the caesarean section operation rooms, and post-anesthesia care unit at Rafidia governmental hospital. Eighty full-term elective caesarean section parturient (Age 18-50 years) with ASA 1 or 2 classification were recruited and randomly allocated into two groups: prophylactic IV ondansetron treatment group and placebo $0.9 \%$ saline control group. The 
primary outcomes were the incidence of spinal anesthesia-induced shivering and hypotension, while secondary outcomes were perioperative bradycardia, nausea, vomiting, headache, pain, pruritus, dizziness and respiratory depression and parturient satisfaction.

Results: Incidence of intraoperative hypotension and dizziness in the ondansetron group was significantly lower than which occurred in the control group $(22.5 \%$ vs. $62.5 \%$ respectively; $\mathrm{P}<0.001$ ), the incidences and intensity of intraoperative shivering in the ondansetron group was lower than the control group $(12.5 \%$ vs. $32.5 \%$ respectively; $\mathrm{P}=0.032)$, Intraoperative nausea intensity in the ondansetron group was lower than control group $(\mathrm{P}=0.049)$.

Postoperatively, the incidence of postoperative dizziness in the ondansetron group was lower than the control group ( $5 \%$ vs. $37.5 \%$ respectively; $\mathrm{P}=0.001$ ), the incidence and intensity of postoperative shivering in the ondansetron group was lower than the control group (12.5\% vs. $37.5 \%$ respectively; $P=0.01$ ). Incidence and intensity of postoperative nausea in the ondansetron group was lower than the control group (17.5\% vs. $40 \%$ respectively; $\mathrm{P}=$ 0.026), the incidence of postoperative vomiting in the ondansetron group was lower than the control group ( $25.5 \%$ vs. $2.5 \%$ respectively; $\mathrm{P}=0.014)$.

Conclusion: Prophylactic $4 \mathrm{mg}$ IV ondansetron can significantly attenuate the incidences of spinal anesthesia-induced shivering and hypotension, dizziness, nausea, and vomiting occurrence and increase parturient satisfaction scale for parturient who undergo caesarean section.

\section{Introduction}

Spinal anesthesia is often used in cesarean section delivery due to its rapid onset, definite motor and sensory blockade, and low risk of local anesthetic systemic toxicity.

52 Furthermore, it offers diverse benefits for both mothers and their developing infant's outcomes, i.e., better oxygenation and acid-base balance, despite of that, it is not free of risks 
54 (Ghani et al., 2015). Spinal-anesthesia-induced shivering and hypotension frequently occur perioperatively, with an incidence of $80 \%$ and 60\%, respectively (Habib, 2012; Tie et al., 2014). These complications have harmful effects on the fetus and the delivering mother, including reduced utero placental perfusion, impaired fetal perfusion and gas exchange, fetal acidemia, serious maternal complications, e.g., reduced cardiac output and diminished cerebral perfusion (Limongi \& Lins, 2011), altered level of consciousness, nausea, and vomiting (Lee, George, \& Habib, 2017).

Hypotension can lead to nausea, vomiting, altered consciousness, an increased risk of aspiration, and reduced uterine-fetal blood flow. The mechanisms that cause hypotension during spinal anesthesia are sympatholysis, where systemic vascular resistance is induced (Langesæter et al., 2008), as well as the activation of Bezold-Jarisch reflex which leads to vasodilatation, bradycardia, and hypotension (Warltier et al., 2003). Several receptors are involved in these changes, including the 5-HT3 receptor. In human studies, 5-HT3 receptor antagonists have been evaluated for their efficacy to prevent spinal anesthesia-induced hypotension, but the results are inconsistent (Ortiz-Gómez et al., 2014; Trabelsi et al., 2015).

Perioperative shivering amplifies the metabolic heat yield up to 6-fold above the baseline metabolic rate (Giesbrecht et al., 1994); increasing the oxygen consumption approximately 200-500\% (Bay, Nunn, \& Prys-Roberts, 1968; Macintyre, Pavlin, \& Dwersteg, 1987). Furthermore, it leads to hypercarbia, hypoxemia, lactic acidosis, and worsening pain sensation (Begum et al., 2008). In addition to that, shivering prolongs hospital stay, may lead to surgical wound infection, decreases immunity, causes coagulopathy, and increases the incidence of cardiac morbidity (Kim et al., 2014; Reynolds et al., 2008). All of this burdens health care facilities and put the patient's overall health status at risk. 
It is worth to mention that, until now there is no consensus regarding the efficacy of ondansetron on the reduction of spinal anesthesia-induced shivering and hypotension.

80 This study primarily carried out to evaluate the efficacy of prophylactic $4 \mathrm{mg}$ intravenous 81 ondansetron on the reduction of spinal anesthesia-induced shivering and hypotension in an 82 obstetric population that undergoes elective cesarean section.

\section{$83 \quad 1.1 \quad$ Problem statement}

84 Spinal anesthesia is often complicated by postoperative hypotension and shivering.

85 Hypotension affects approximately $50 \%$ of the obstetric population (Klöhr et al., 2010). A drop in arterial blood pressure can lead to nausea and vomiting, altered consciousness, an increased risk of aspiration, and reduced uterine-fetal blood flow. The mechanisms that cause hypotension during spinal anesthesia include sympatholysis, which induces a decrease in systemic vascular resistance (Langesæter et al., 2008), as well as the Bezold-Jarisch reflex. The latter phenomenon leads to vasodilation, bradycardia, and hypotension (Warltier et al., 2003). Several receptors are involved in these changes, including the 5-HT3 receptor. Antagonists for this receptor can block the Bezold-Jarisch reflex in animal models (Yamano et al., 1995). In human studies, 5-HT3 receptor antagonists have been evaluated for their

94 efficacy to prevent spinal-anesthesia-related hypotension, but the results are inconsistent

95 (Ortiz-Gómez et al., 2014; Trabelsi et al., 2015).

96 Preoperative shivering amplifies the metabolic heat yield up to 6-fold above the baseline

97 metabolic rate (Giesbrecht et al., 1994); it is clinically associated with different frequencies

98 of tonic or clonic skeletal muscular hyperactivity (Javaherforoosh et al., 2009).This

99 augmented muscular activity increases oxygen consumption approximately 200-500\% (Bay,

100 Nunn, \& Prys-Roberts, 1968; Macintyre, Pavlin, \& Dwersteg, 1987). Further, it leads to

101 hypercarbia, hypoxemia, and lactic acidosis, all of which worsen pain sensations (Begum et 
al., 2008). This excited muscular activity compromises myocardial function and worsens morbidity rates, especially when the patient has preexisting diminished myocardial oxygen

104 flow, e.g. arteriosclerosis (Alfonsi, 2001; Ciofolo et al., 1989). These conditions will affect

105 uteroplacental blood flow. Some of used drugs for treating post-anesthesia shivering are

106 meperidine, tramadol, and clonidine, but all of these have adverse effects, including sedative

107 effects, nausea, vomiting, bradycardia, and hypotension. Postoperative shivering prolongs

108 hospital stays, may lead to surgical wound infection, decreases immunity, causes

109 coagulopathy, and increases the incidence of cardiac morbidity (Kim et al., 2014; Reynolds et

110 al., 2008). These morbidities burden health care facilities and put the patient's overall health

111 status at risk.

\section{$112 \quad 1.2 \quad$ Study objectives}

113 This study was conducted to achieve the following objectives:

114 a) Primarily, to determine the efficacy of prophylactic intravenous ondansetron

115 on the reduction of spinal-anesthesia-induced shivering and hypotension in an

116 obstetric population that undergoes elective caesarean sections.

117 b) Secondarily, to determine the effect of ondansetron on prevention of 118 postoperative spinal anesthesia complications, including bradycardia, nausea, 119 vomiting, headache, pain, pruritus, dizziness, and respiratory depression.

\subsection{Significance of the Study}

122 Spinal-anesthesia-induced shivering and hypotension have significant negative consequences

123 on the mother and infant during cesarean section. These factors can increase the length of a 
124 hospital stay and cause financial and other burdens to health services. Conducting this study

125 will help to whether ondansetron can reduce these complications. Moreover, earlier studies

126 suggest that avoiding shivering will provide valuable benefits in patients and promote a

127 superior prognosis (Kurz et al., 1996). Notably, this study is the first of its kind in Palestine.

128 The results should provide benefits to our patients and their relatives by decreasing their

129 preventable suffering and to our hospitals by decreasing patients' hospitalization and,

130 consequently, the economic burden on these health care facilities.

\section{$131 \quad 1.4 \quad$ Study methodology}

\section{Study design}

133

134 The study was conducted as a prospective, cohort, randomized, double-blinded, placebo-

135 controlled trial (RCT). This design was adopted due the strength of the hierarchy of scientific

136 evidence, namely, reduced bias and more accurate results.

\section{Clinical Trial Registration}

138 This clinical trial registered at Thai Clinical Trials Registry (TCTR) on 22/08/2020 with

139 registration ID: TCTR20200825001.

140

143 The target population was a cohort of full-term obstetrics participants with an ASA I or II

144 classification who planned for elective caesarean section at Rafidia Governmental Surgical

145 Hospital. 
Eligibility (inclusion and exclusion criteria)

153

154

155

156

157

158

159

160

161

162

163

164

165

166

167

168

169

170

171

172

173

174

175

176

177

178

179

180

181

182

183

\begin{tabular}{|c|c|}
\hline Inclusion criteria & Exclusion criteria \\
\hline $\begin{array}{lll}\text { 1. Patients undergoing elective } \\
\text { caesarean sections surgery }\end{array}$ & 1. Pre-existing or gestational hypertension \\
\hline 2. $18-50$ years old & 2. History of allergy to ondansetron drug \\
\hline $\begin{array}{lllll}\text { 3. } & \begin{array}{l}\text { American } \\
\text { Anesthesiologists } \\
\text { classification }\end{array} & \text { Society } & & \text { of } \\
\text { (ASA) } & \text { I or II } \\
\end{array}$ & 3. Cardiovascular or cerebrovascular diseases \\
\hline \multirow[t]{6}{*}{ 4. No major systemic diseases } & 4. Urgent caesarean sections \\
\hline & 5. Mothers with suspected deteriorated foetuses \\
\hline & 6. Contraindications for spinal block \\
\hline & 7. Thyroid disorders \\
\hline & 8. Participant temperature $>38^{\circ} \mathrm{C}$ or $<36.5^{\circ} \mathrm{C}$ \\
\hline & $\begin{array}{l}\text { 9. Patients likely to receive intraoperative blood } \\
\text { transfusion }\end{array}$ \\
\hline
\end{tabular}

\section{Sample size calculation}

The sample size was calculated using the tools at https://clincalc.com/stats/samplesize.aspx, an evidence-based clinical decision support tools and calculators for medical professionals.

The following assumptions were used to calculate the sample size:

- The accepted alpha is $5 \%$ and beta is $20 \%$.

- The median incidence of spinal-anesthesia-induced shivering in a review of 21 studies is $55 \%$. It is expected to go down to $22.5 \%$ with ondansetron treatment. A sample size of 34 subjects in each group would be required to detect this difference.

- The incidence of spinal hypotension during caesarean delivery is $77 \%$, which would be expected to decrease to $45 \%$ with ondansetron treatment. A sample size of 35 subjects in each group would be required to detect this difference. 
187 According to this tool and these assumptions, we decided to increase the sample size to 40 patients per group (a total of 80 participants) who met the inclusion criteria.

\section{Randomization}

The participants who met the inclusion criteria and according to randomization list formatted by www.randomization.com, the participants were randomized into two groups: The treatment group received intravenous ondansetron (4 mg diluted in $10 \mathrm{ml} 0.9 \%$ saline) prior to spinal anesthesia induction, while the control received intravenous placebo (10 $\mathrm{ml}$ of $0.9 \%$ saline) prior to spinal anesthesia induction. There were two anesthesiologists, the first assigned for drugs preparation and dilution in indistinguishable syringes, the second anesthesiologists assigned for drug administration and both anesthesiologists not involved in data collection procedure.

\section{Blinding}

202 This study was double blinded: the participants, and the data recorder were blinded in the study, the anesthesiologist who prepared the study drugs were not blinded.

\section{Measured Outcomes:}

206

207 Primarily, the outcomes were to determine the efficacy of prophylactic intravenous ondansetron on the incidence of spinal anaesthesia-induced shivering and hypotension in an obstetric population that undergoes elective caesarean section; secondarily, to determine the

210 effect of ondansetron on the prevention of postoperative spinal anaesthesia complications,

211 including bradycardia, nausea, vomiting, headache, pain, pruritus, dizziness, respiratory

212 depression, and on overall participants satisfaction score. 


\section{Measurement and data collection procedure}

Study observations and hemodynamic parameters were measured preoperatively (baseline),

217 intraoperatively, and postoperatively. For both groups, study observations were recorded every $3 \mathrm{~min}$ until the end of the operation and every $5 \mathrm{~min}$ (for $15 \mathrm{~min}$ total) in the postanaesthesia care unit (PACU), which is the total time participant stayed in PACU at the

220 Rafedia hospital. These observations included systolic blood pressure (SBP), diastolic blood pressure (DBP), mean arterial pressure (MAP) and those measured non-invasively, heart rate (HR), respiratory rate (RR) via cardiac monitor with chest leads, peripheral capillary oxygen concentration $(\mathrm{SpO} 2)$ via pulse oximeter, and Axillary temperature $(\mathrm{T})$ via digital thermometer. Intraoperative and postoperative shivering incidence and severity, hypotension incidence, nausea and vomiting incidence and severity, incidence of used meperidine to treat shivering, the incidence of the use of hypotension rescue medications (ephedrine, phenylephrine) and the participants overall satisfaction level of 0-4 likert type scale.

Perioperative pain and headache were measured using the numerical rating scale (NRS), which is a subjective measure in which individuals rate their pain on an eleven-point

230 numerical scale, the scale is composed of 0 to 10 , where NRS scores $\leq 5$ correspond to mild, scores of 6-7 to moderate and scores $\geq 8$ to severe pain in terms of pain-related interference with functioning and 10 is worst imaginable pain (Boonstra et al., 2016), this scale validated by (Ferreira-Valente, Pais-Ribeiro and Jensen, 2011). Nausea and vomiting severity were measured using the 0-5 numeric rating scale (NRS), where $0=$ none, $1=$ anticipated, $2=$ mild,

$2353=$ moderate, $4=$ great, $5=$ sever, and this scale validated by (Halpin, Huckabay, Kozuki and 236 Forsythe, 2010). Shivering was graded using the previously validated 5-item scale (Crossley

237 \& Mahajan, 1994; Tsai \& Chu, 2001), where $0=$ no shivering; $1=$ peripheral

238 vasoconstriction or piloerection but not visible shivering; $2=$ shivering in one muscle group 239 only, 3 = shivering in $\geq 1$ muscle group but not generalized shivering; and $4=$ generalized 
240 shivering. Grade 3 or 4 shivering for at least 3 min was considered a positive shivering sign.

24131 A positive shivering sign and low-grade shivering were annoying for the participants and

242 managed with intravenous $0.5 \mathrm{mg} / \mathrm{kg}$ meperidine.

\section{Anaesthesia protocol}

A physical assessment was performed by anesthesiologist, and $\mathrm{CBC}$ platelet tests were assessed for all participants. The anesthesia machine, anesthesia equipment, and spinal anesthesia drugs were checked for proper functioning. Standard monitoring precautions and guidelines from the American Surgical Association (ASA) were followed, including continuous electrocardiography (ECG), non-invasive BP measurement, and pulse oximeter (asahq.org, 2020). The operating rooms were maintained at $24^{\circ} \mathrm{C}$ by air conditioning. An intravenous cannula (18-20 Fr) was inserted; $500 \mathrm{~mL} 0.9 \%$ saline solution was given to all patients before the spinal injection per the targeted hospital protocol. An anesthesiologist performed the spinal puncture by pencil point spinal needle (27 Fr) between the L3-L4 or L4- L5 vertebrae with the participant in a sitting position on the side of the operation table. The participants were given $7.5 \mathrm{mg}(1.5 \mathrm{ml})$ Marcaine Heavy $0.5 \%$ (bupivacaine) mixed with $20 \mu \mathrm{g}$ fentanyl and $200 \mu \mathrm{g}$ morphine into the subarachnoid space. The patients were placed in the supine position immediately after the spinal anesthesia injection. The anesthesiologists assessed dermatomes levels after administering subarachnoid block every minute using

260 alcohol-soaked swap authorization only given for the surgeon only when the level of block reached T5. Supplemental oxygen $(5 \mathrm{~L} / \mathrm{min})$ via a simple face mask was provided until the end of delivery. Vital signs changes and adverse spinal anesthesia effects were recorded periodically as prescribed. 


\section{Data Analysis}

The data were analysed with SPSS version 22 for Windows (IBM Corp., Armonk, NY, USA). Data normality was tested using Kolmogorov-Smirnov test. The data were not normally distributed. Thus, nonparametric statistics tests were used. The Scale data are expressed as the median (quartile 1 [Q1]-quartile 3 [Q3]). The groups were compared with the Mann-Whitney U Test. Categorical variables (YES/NO questions) were statistically analysed with Chi-square tests have been used. A P value $\leq 0.05$ was considered to indicate a statistically significant difference.

\section{Declarations}

\section{Ethical approval and consent to participate}

280 This study was conducted in adherence to the Helsinki declaration guidelines and institutional review board (IRB) approval taken from An-Najah National University IRB board. A Palestinian Ministry of Health facilitation letter allowing data collection in Rafedia Governmental Hospital also have been taken. Prior to participation, all participants signed a

284 thoroughly explained informed consent form.

\section{Consent for publication}

286 Not applicable

\section{Availability of data and materials}

Data used to support the findings of this study are available from the corresponding author

289 (Ahmad M Salahat, E-mail: Ahmad.salahatt@gmail.com) upon reasonable request.

\section{Competing interests}

291 The authors declare that there is no conflict of interest regarding the publication of this paper. 
294 No funding was available, the study was self-financed by the principal author.

\section{Authors' contributions}

296 1. Ahmad Salahat (The Corresponding author): planned and conceived the study i.e., do the

297 study design and study implementation, research writing, results' SPSS analysis.

298 2. Dr. Adham Abu Taha: The study Academic supervisor

299 3. Dr. Nouraldin Almasri: The study Clinical supervisor- Rafidia governmental hospital

300 4. Mr. Essa Sweity: Assisted in both SPSS analysis and study writing process.

\section{Acknowledgements}

303 I would like to express my gratitude to my awesome academic supervisor Dr.

304 Adham Abu Taha for his precious support and engagement through the learning 305 process of this master thesis. Thanks for Dr. Nouraldin Almasri for his close 306 support at clinical site. Furthermore, I would like to thank the head of Nursing 307 and Midwifery College Dr. Aidah Alkaissi for her support on the whole way to 308 be an impactful CRNA. Last but not least, I would also like to thank Dr. Saed 309 Zyoud for his endless help and support in the statistical analysis of this project.

\section{Corresponding Author' information}

312 Ahmad Salahat, CRNA, MSN, RN

313 CCU, ICU, NICU, PICU-RN Registered Nurse

314 Lecturer at Andaleeb Al-Amad college for Nursing and Midwifery

315 Palestine, Nablus. 
317 Ninety women were assessed for eligibility; 10 did not meet the inclusion criteria, were

318 contraindicated for spinal anesthesia, and converted to general anesthesia. The remaining 80

319 women were enrolled and randomized into the treatment or control group, Consort diagram

320 (Fig. 1). There were no differences in demographic data between the groups, $\mathrm{p}$ value was >

3210.05 (Table 2).

322 As tables $(3,4,5$, and 6$)$ show, between both study groups, there was a significant difference

323 regarding the following: incidence of intraoperative hypotension and dizziness; there were

$32425 / 40$ cases $(62.5 \%)$ in the control group vs. $9 / 40$ cases $(22.5 \%)$ in ondansetron group $(P<$

$3250.001)$, incidences and intensity of intraoperative shivering there were $13 / 40$ cases $(32.5 \%)$

326 in control group vs. $5 / 40$ cases $(12.5 \%)$ in ondansetron group $(P=0.032)$. Intraoperative

327 nausea intensity was lower in the ondansetron group $(P=0.049)$.

328 Postoperatively, incidence of dizziness where 15/40 cases (37.5\%) in the control group vs.

$3292 / 40$ cases $(5 \%)$ in the ondansetron group $(P=0.001)$, incidence and intensity of

330 postoperative shivering where $15 / 40$ cases $(37.5 \%)$ in control group vs. only $5 / 40$ cases (12.5

$\%)$ in ondansetron group $(P=0.010)$. Incidence and intensity of postoperative nausea where $(P=0.026)$, postoperative vomiting, incidence where $9 / 40$ cases $(25.5 \%)$ in control group vs. only $1 / 40$ cases $(2.5 \%)$ in ondansetron group $(P=0.014)$. 
Table (2): Demographic data of Participants

VARIABLE

\section{Ondansetron}

Age (years)

29.5 [27 - 32.7]

Control

Weight $(\mathrm{kg})$

$83.5[78.2-96.5]$

28 [25.2-30]

P value 347

Parity

$3[1.25-4]$

80.5 [73 - 86.7]

0.154349

Gravidity

$3[2-4]$

$3[2-4]$

$0.052 \quad 350$

Gestational age (weeks)

$40[40-40]$

$3[2-5]$

0.670

History of cesarean section

2 [1-3]

$39[38-40]$

0.122

351

Time of delivery

$11[10-12]$

$2[1-3]$

0.637

0.323

352

$11[9.2-12]$

$0.723 \quad 353$

CONSORT Flow Diagram (Fig. 1)

\section{Enrolment}

Assessed for eligibility $(n=90)$

Excluded $(n=10)$

- Not meeting inclusion criteria $(n=10)$

- Declined to participate $(n=0)$

- Other reasons $(n=0)$

360

361

Randomized $(\mathrm{n}=80)$

362
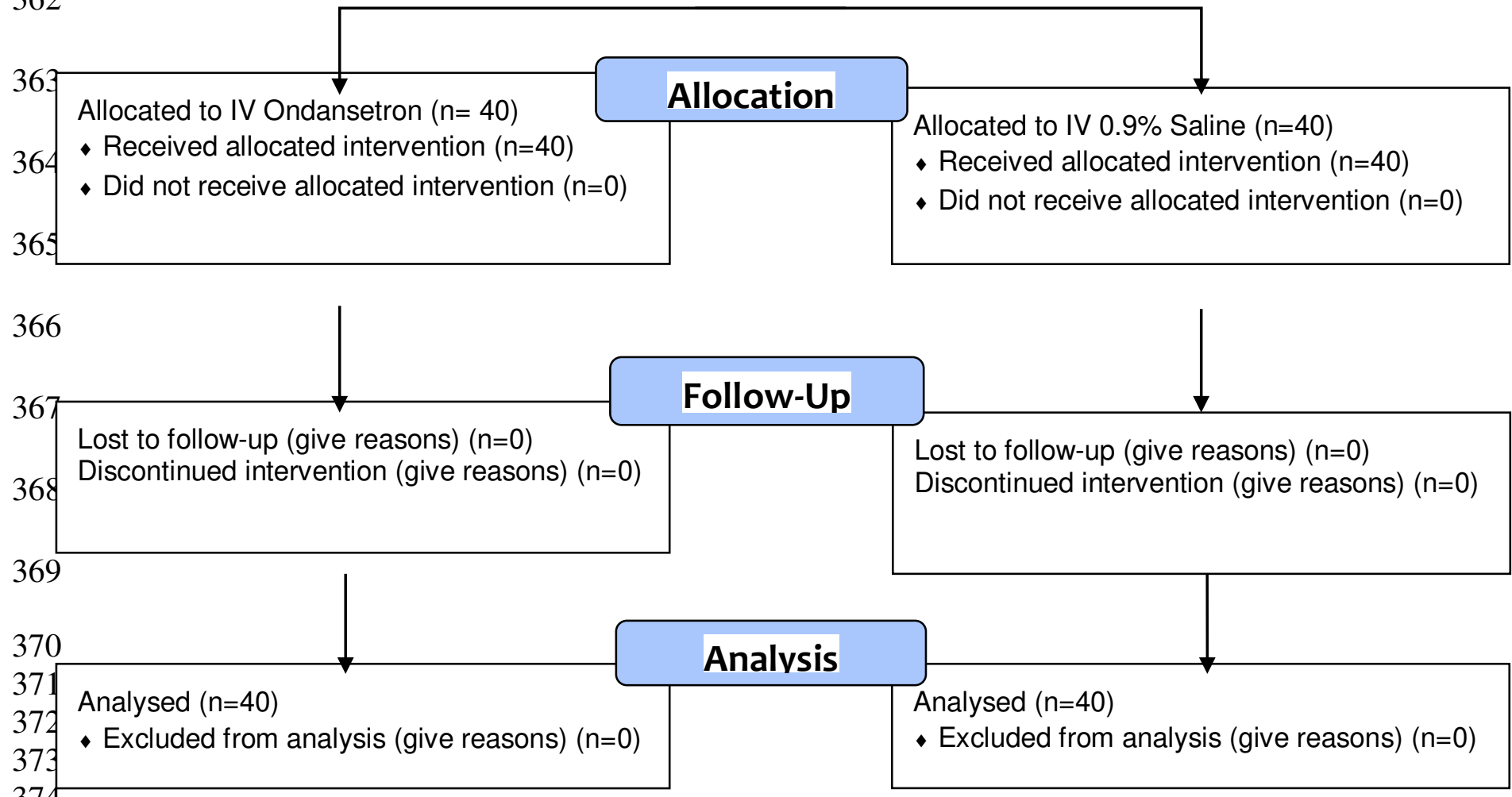


\begin{tabular}{|c|c|c|c|}
\hline VARIABLE & $\begin{array}{l}\text { Ondansetron } \\
\text { Median [Q1-Q3] }\end{array}$ & $\begin{array}{l}\text { Control } \\
\text { Median [Q1-Q3] }\end{array}$ & $\begin{array}{l}P \\
\text { value }\end{array}$ \\
\hline Baseline systolic blood pressure & $121[120-123]$ & $121[119-122]$ & 0.134 \\
\hline Baseline diastolic blood pressure & $71[61-81]$ & $67[62-80]$ & 0.885 \\
\hline Baseline mean arterial pressure & $81[79-84]$ & $80[78-81]$ & 0.053 \\
\hline Baseline heart rate & $81[78-90]$ & $81[75-90]$ & 0.622 \\
\hline Baseline respiratory rate & $18[15-20]$ & $18[15-19]$ & 0.805 \\
\hline Baseline peripheral capillary oxygen saturation & $100[100-100]$ & $100[99-100]$ & 0.250 \\
\hline Baseline temperature & $37[36.8-37.1]$ & $36.9[36.8-37.1]$ & 0.200 \\
\hline Induction Systolic blood pressure & $122[109-129]$ & $101[90-115]$ & $<0.001 *$ \\
\hline Induction diastolic blood pressure & $66[57-72]$ & $60[55-63]$ & $0.019^{*}$ \\
\hline Induction mean arterial pressure & $81[74-88]$ & $70[67-80]$ & $0.001 *$ \\
\hline Induction heart rate & $80[75-89]$ & $77[71-82]$ & 0.171 \\
\hline Induction respiratory rate & $18[14-19]$ & $16[14-18]$ & 0.176 \\
\hline Induction peripheral capillary oxygen saturation & 99 [98 -99] & 98 [98 -99] & $0.050^{*}$ \\
\hline Induction temperature & $37[36.8-37.1]$ & $36.8[36.6-37.1]$ & $0.047 *$ \\
\hline 3-minute Systolic blood pressure & $118[110-130]$ & $100[88-114]$ & $<0.001 *$ \\
\hline 3-minute diastolic blood pressure & $66[56-74]$ & $58[55-61]$ & $0.001 *$ \\
\hline 3-minute mean arterial pressure & $85[73-90]$ & $69[67-77]$ & $<.001^{*}$ \\
\hline 3-minute heart rate & $80[75-88]$ & $73[70-81]$ & $0.004 *$ \\
\hline 3-minute respiratory rate & $17[14-19]$ & $16[14-18]$ & 0.178 \\
\hline 3-minute peripheral capillary oxygen saturation & $99[99-99]$ & 99 [ 98- 99] & 0.330 \\
\hline 3-minute temperature & $36.9[36.7-37.1]$ & $36.5[35.8-37.1]$ & $0.029^{*}$ \\
\hline 6-minute Systolic blood pressure & $122[113-130]$ & $111[103-118]$ & $<0.001 *$ \\
\hline 6-minute diastolic blood pressure & $66[60-71]$ & $62[60-65]$ & $0.031 *$ \\
\hline 6-minute mean arterial pressure & $85[78-88]$ & $77[72-80]$ & $<0.001 *$ \\
\hline 6-minute heart rate & $80[75-87]$ & $75[72-80]$ & $0.004^{*}$ \\
\hline 6-minute respiratory rate & 18 [14 -19] & $16[13-19]$ & 0.174 \\
\hline 6-minute peripheral capillary oxygen saturation & 99 [99 -99] & 99 [98 -99] & $0.038^{*}$ \\
\hline 6-minute temperature & $36.9[36.637 .1-]$ & $36.3[35.6-37.1]$ & $0.026^{*}$ \\
\hline 9-minute Systolic blood pressure & $120[114-130]$ & $117[111-120]$ & $0.006^{*}$ \\
\hline 9-minute diastolic blood pressure & $70[62-75]$ & $67[60-75]$ & 0.806 \\
\hline 9-minute mean arterial pressure & $84[77-91]$ & $78[75-80]$ & $<0.001 *$ \\
\hline 9-minute heart rate & $81[78-88]$ & $78[70-81]$ & $0.008^{*}$ \\
\hline 9-minute respiratory rate & 18 [14 -19] & $15[12-18]$ & 0.168 \\
\hline 9-minute peripheral capillary oxygen saturation & $99[99-100]$ & $99[98-100]$ & 0.055 \\
\hline 9-minute temperature & $36.9[36.8-37.1]$ & $36.5[35.4-37.2]$ & 0.071 \\
\hline
\end{tabular}


Table 3: Intraoperative hemodynamics (continued)

\begin{tabular}{llll} 
VARIABLE & $\begin{array}{l}\text { Ondansetron } \\
\text { Median [Q1-Q3] }\end{array}$ & $\begin{array}{l}\text { Control } \\
\text { Median [Q1-Q3] }\end{array}$ & $\begin{array}{l}\text { P } \\
\text { value }\end{array}$ \\
\hline 12-minute Systolic blood pressure & $120[116-128]$ & $118[114-121]$ & 0.066 \\
12-minute diastolic blood pressure & $71[63-80]$ & $70[61-80]$ & 0.885 \\
12-minute mean arterial pressure & $82[79-89]$ & $80[78-81]$ & $0.004^{*}$ \\
12-minute heart rate & $80[78-86]$ & $77[69-81]$ & $0.001^{*}$ \\
12-minute respiratory rate & $17[14-19]$ & $15[12-18]$ & 0.104 \\
12-minute peripheral capillary oxygen saturation & $99[99-99]$ & $99[98-99]$ & 0.196 \\
12-minute temperature & $36.9[36.8-37.2]$ & $36.5[35.6-37.2]$ & 0.103 \\
15-minute Systolic blood pressure & $121[121-124]$ & $120[116-122]$ & $0.005^{*}$ \\
15-minute diastolic blood pressure & $76[66-80]$ & $76[66-80]$ & 0.912 \\
15-minute mean arterial pressure & $82[79-88]$ & $80[78-81]$ & $0.003^{*}$ \\
15-minute heart rate & $81[78-87]$ & $77[69-82]$ & $0.029^{*}$ \\
15-minute respiratory rate & $15[14-18]$ & $15[12-18]$ & 0.313 \\
15-minute peripheral capillary oxygen saturation & $99[99-99]$ & $99[98-99]$ & 0.624 \\
15-minute temperature & $36.7[36.7-37.1]$ & $36[35.4-37.1]$ & $0.030^{*}$ \\
\hline
\end{tabular}

\section{Table 4: Post anesthesia care unit (PACU) hemodynamics}

\begin{tabular}{llll}
\hline VARIABLE & $\begin{array}{l}\text { Ondansetron } \\
\text { Median [Q1-Q3] }\end{array}$ & $\begin{array}{l}\text { Control } \\
\text { Median [Q1-Q3] }\end{array}$ & $\begin{array}{l}\text { Palue } \\
\text { valu }\end{array}$ \\
\hline PACU 1-minute systolic blood pressure & $121[112-129]$ & $118[111-120]$ & 0.032 \\
PACU 1-minute diastolic blood pressure & $66[58-74]$ & $66[61-78]$ & 0.170 \\
PACU 1 minute mean arterial pressure & $82[87-89]$ & $78[75-81]$ & $0.001^{*}$ \\
PACU 1 minute heart rate & $81[78-89]$ & $80[76-84]$ & 0.381 \\
PACU 1-minute respiratory rate & $18[14-20]$ & $18[14-19]$ & 0.413 \\
PACU 1-minute peripheral capillary oxygen saturation & $99[99-100]$ & $98[98-99]$ & $<.001^{*}$ \\
PACU 1 minute temperature & $36.9[36.8-37.1]$ & $36.4[35.8-37.0]$ & $0.004^{*}$ \\
PACU 5-minute systolic blood pressure & $121[112-128]$ & $116[111-120]$ & $0.022^{*}$ \\
PACU 5-minute diastolic blood pressure & $67[61-74]$ & $66[60-78]$ & 0.889 \\
PACU 5 mean arterial pressure & $85[78-89]$ & $78[74-80]$ & $<0.001^{*}$ \\
PACU 5-minute heart rate & $81[78-87]$ & $78[72-82]$ & $0.022^{*}$ \\
PACU 5-minute respiratory rate & $18[15-19]$ & $18[14-18]$ & 0.165 \\
PACU 5-minute peripheral capillary oxygen saturation & $99[98-100]$ & $98[97-99]$ & $<0.001^{*}$ \\
PACU 5-minute temperature & $36.9[36.7-37.1]$ & $36.2[35.6-37.1]$ & $0.006^{*}$ \\
PACU 15-minute systolic blood pressure & $122[115-129]$ & $119[113-121]$ & $0.010^{*}$ \\
PACU 15-minute diastolic blood pressure & $67[61-77]$ & $68[61-77]$ & 0.885 \\
PACU 15 mean arterial pressure & $81[79-89]$ & $77[74-80]$ & $<0.001^{*}$ \\
PACU 15-minute heart rate & $81[78-88]$ & $80[72-82]$ & $0.050^{*}$ \\
PACU 15-minute respiratory rate & $18[16-19]$ & $15[14-18]$ & $0.003^{*}$ \\
PACU 15-minute peripheral capillary oxygen saturation & $99[99-100]$ & $99[98-99]$ & $0.022^{*}$ \\
PACU 15-minute temperature & $36.9[36.7-37.2]$ & $36.5[35.6-37.1]$ & $0.010^{*}$
\end{tabular}


Table 5: Intraoperative complications

\begin{tabular}{|c|c|c|c|c|c|}
\hline Variable & & $\begin{array}{l}\text { Total } \\
\text { n }(\%)\end{array}$ & $\begin{array}{l}\text { Ondansetron } \\
\text { n }(\%)\end{array}$ & $\begin{array}{l}\text { Control } \\
\text { n }(\%)\end{array}$ & $\begin{array}{l}P \\
\text { value }\end{array}$ \\
\hline \multirow{2}{*}{$\begin{array}{l}\text { Intraoperative } \\
\text { Bradycardia }\end{array}$} & Yes & $3(3.8 \%)$ & $0(0.0 \%)$ & $3(7.5 \%)$ & \multirow[t]{2}{*}{0.241} \\
\hline & NO & $77(96.3 \%)$ & $40(100 \%)$ & $37(92.5 \%)$ & \\
\hline \multirow{2}{*}{$\begin{array}{l}\text { Intraoperative } \\
\text { Hypotension }\end{array}$} & Yes & $34(42.5 \%)$ & $9(22.5 \%)$ & $25(62.5 \%)$ & \multirow[t]{2}{*}{$<0.001^{*}$} \\
\hline & NO & $46(57.5 \%)$ & $31(77.5 \%)$ & $15(37.5 \%)$ & \\
\hline \multirow{2}{*}{$\begin{array}{l}\text { Intraoperative } \\
\text { Headache }\end{array}$} & Yes & $16(20 \%)$ & $5(12.5 \%)$ & $11(27.5 \%)$ & \multirow[t]{2}{*}{0.094} \\
\hline & NO & $64(80 \%)$ & $35(87.5 \%)$ & $29(72.5 \%)$ & \\
\hline \multirow[t]{2}{*}{ Intraoperative Pain } & Yes & $27(33.8 \%)$ & $10(25 \%)$ & $17(42.5 \%)$ & \multirow[t]{2}{*}{0.098} \\
\hline & NO & $53(66.3 \%)$ & $30(75 \%)$ & $23(57.5 \%)$ & \\
\hline \multirow{2}{*}{$\begin{array}{l}\text { Intraoperative } \\
\text { Pruritus }\end{array}$} & Yes & $30(37.5 \%)$ & $11(27.5 \%)$ & $19(47.5 \%)$ & \multirow[t]{2}{*}{0.065} \\
\hline & NO & $50(62.5 \%)$ & $29(72.5 \%)$ & $21(52.5 \%)$ & \\
\hline \multirow[t]{2}{*}{ Intraoperative shivering } & Yes & $18(22.5 \%)$ & $5(12.5 \%)$ & $13(32.5 \%)$ & \multirow[t]{2}{*}{$0.032^{*}$} \\
\hline & NO & $62(77.5 \%)$ & $35(87.5 \%)$ & $27(67.5 \%)$ & \\
\hline \multirow[t]{2}{*}{ Intraoperative Nausea } & Yes & $26(32.5 \%)$ & $10(25 \%)$ & $16(40 \%)$ & \multirow[t]{2}{*}{0.152} \\
\hline & NO & $45(67.5 \%)$ & $30(75 \%)$ & $24(60 \%)$ & \\
\hline \multirow[t]{2}{*}{ Intraoperative Vomiting } & Yes & $6(7.5 \%)$ & $1(2.5 \%)$ & $5(12.5 \%)$ & \multirow[t]{2}{*}{0.201} \\
\hline & NO & $74(92.5 \%)$ & $39(97.5 \%)$ & $35(87.5 \%)$ & \\
\hline \multirow{2}{*}{$\begin{array}{l}\text { Intraoperative } \\
\text { respiratory depression }\end{array}$} & Yes & $4(5 \%)$ & $0(0 \%)$ & $4(10 \%)$ & \multirow[t]{2}{*}{0.116} \\
\hline & NO & $\pi$ & 4 & 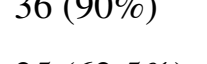 & \\
\hline \multirow[t]{2}{*}{ Intraoperative Dizziness } & $\begin{array}{l}\text { Yes } \\
\text { NO }\end{array}$ & $\begin{array}{l}34(42.5 \%) \\
46(57.5 \%)\end{array}$ & $\begin{array}{l}9(22.5 \%) \\
31(77.5 \%)\end{array}$ & $\begin{array}{l}25(62.5 \%) \\
15(37.5 \%)\end{array}$ & $<0.001^{*}$ \\
\hline & \multicolumn{2}{|c|}{$\begin{array}{l}\text { Ondansetron } \\
\text { Median [Q1-Q3] }\end{array}$} & \multicolumn{2}{|c|}{$\begin{array}{l}\text { Control } \\
\text { Median [Q1-Q3] }\end{array}$} & $P$ value \\
\hline $\begin{array}{l}\text { Intraoperative pain } \\
(0-10 \text { NPRS scale })\end{array}$ & \multicolumn{2}{|c|}{$0.00[0.00-1.0]$} & \multicolumn{2}{|l|}{$0.00[0.00-3.0]$} & 0.107 \\
\hline $\begin{array}{l}\text { Intraoperative shivering } \\
(0-4 \text { scale })\end{array}$ & \multicolumn{2}{|c|}{$0.00[0.00-0.00]$} & \multicolumn{2}{|l|}{$0.00[0.00-1.0]$} & $0.010^{*}$ \\
\hline $\begin{array}{l}\text { Intraoperative nausea } \\
(0-6 \text { scale })\end{array}$ & \multicolumn{2}{|c|}{$0.00[0.00-0.75]$} & \multicolumn{2}{|l|}{$0.00[0.00-0.30]$} & $0.049^{*}$ \\
\hline
\end{tabular}


Table 6: Postoperative complication

\begin{tabular}{|c|c|c|c|c|c|}
\hline Variable & & Total: n (\%) & $\begin{array}{l}\text { Ondansetron: } \\
\text { n }(\%)\end{array}$ & $\begin{array}{l}\text { Control: } \\
\text { n }(\%)\end{array}$ & $\begin{array}{l}P \\
\text { value }\end{array}$ \\
\hline \multirow{2}{*}{$\begin{array}{l}\text { Post-operative } \\
\text { Bradycardia }\end{array}$} & Yes & $0(0 \%)$ & $0(0 \%)$ & $0(0 \%)$ & \multirow[t]{2}{*}{$>0.999$} \\
\hline & NO & $80(100 \%)$ & $40(100 \%)$ & $40(100 \%)$ & \\
\hline \multirow{2}{*}{$\begin{array}{l}\text { Post-operative } \\
\text { Hypotension }\end{array}$} & Yes & $9(11.3 \%)$ & $3(7.5)$ & $6(15 \%)$ & \multirow[t]{2}{*}{0.481} \\
\hline & NO & $71(88.8)$ & $37(92.5)$ & $34(85 \%)$ & \\
\hline \multirow{2}{*}{$\begin{array}{l}\text { Post-operative } \\
\text { headache }\end{array}$} & Yes & $12(15 \%)$ & $6(15 \%)$ & $6(15 \%)$ & \multirow[t]{2}{*}{1.000} \\
\hline & NO & $68(85 \%)$ & $34(85 \%)$ & $34(85 \%)$ & \\
\hline \multirow{2}{*}{$\begin{array}{l}\text { Post-operative } \\
\text { pain }\end{array}$} & Yes & $14(17.5 \%)$ & $6(15 \%)$ & $8(20 \%)$ & \multirow[t]{2}{*}{0.556} \\
\hline & NO & $66(82.5 \%)$ & $34(85 \%)$ & $32(80 \%)$ & \\
\hline \multirow{2}{*}{$\begin{array}{l}\text { Post-operative } \\
\text { pruritus }\end{array}$} & Yes & $7(8.8 \%)$ & $2(5 \%)$ & $5(12.5 \%)$ & \multirow[t]{2}{*}{0.432} \\
\hline & NO & $77(91.3 \%)$ & $38(95 \%)$ & $35(87.5 \%)$ & \\
\hline \multirow{2}{*}{$\begin{array}{l}\text { Post-operative } \\
\text { shivering }\end{array}$} & Yes & $20(25 \%)$ & $5(12.5 \%)$ & $15(37.5 \%)$ & \multirow[t]{2}{*}{$0.010^{*}$} \\
\hline & NO & $60(75 \%)$ & $35(87.5 \%)$ & $25(62.5 \%)$ & \\
\hline \multirow{2}{*}{$\begin{array}{l}\text { Post-operative } \\
\text { nausea }\end{array}$} & Yes & $23(28.8 \%)$ & $7(17.5 \%)$ & $16(40 \%)$ & \multirow[t]{2}{*}{$0.026^{*}$} \\
\hline & NO & $57(71.3 \%)$ & $33(82.5 \%)$ & $24(60 \%)$ & \\
\hline \multirow{2}{*}{$\begin{array}{l}\text { Post-operative } \\
\text { vomiting }\end{array}$} & Yes & $10(12.5 \%)$ & $1(2.5 \%)$ & $9(22.5 \%)$ & \multirow[t]{2}{*}{$0.014^{*}$} \\
\hline & NO & $70(87.5 \%)$ & $39(97.5 \%)$ & $31(77.5 \%)$ & \\
\hline $\begin{array}{l}\text { Respiratory } \\
\text { depression }\end{array}$ & $\begin{array}{l}\text { Yes } \\
\text { NO }\end{array}$ & $\begin{array}{l}1(1.25 \%) \\
79(98.75 \%)\end{array}$ & $\begin{array}{l}0(0 \%) \\
40(100 \%)\end{array}$ & $\begin{array}{l}1(2.5 \%) \\
39(97.5 \%)\end{array}$ & 0.317 \\
\hline \multirow[t]{2}{*}{$\begin{array}{l}\text { Post-operative } \\
\text { dizziness }\end{array}$} & $\begin{array}{l}\text { Yes } \\
\text { NO }\end{array}$ & $\begin{array}{l}17(21.3 \%) \\
63(78.8 \%)\end{array}$ & $\begin{array}{l}2(5 \%) \\
38(95 \%)\end{array}$ & $\begin{array}{l}15(37.5 \%) \\
25(62.5 \%)\end{array}$ & $0.001^{*}$ \\
\hline & \multicolumn{2}{|c|}{$\begin{array}{l}\text { Ondansetron group } \\
\text { Median [Q1-Q3] }\end{array}$} & $\begin{array}{l}\text { Control } \\
\text { Median [Q1-Q3] }\end{array}$ & & $\begin{array}{l}P \\
\text { value }\end{array}$ \\
\hline $\begin{array}{l}\text { PACU pain } \\
0-10 \text { scale }\end{array}$ & \multicolumn{2}{|c|}{$0.00[0.00-0.00]$} & \multicolumn{2}{|l|}{$0.00[0.00-0.00]$} & 0.537 \\
\hline $\begin{array}{l}\text { PACU } \\
\text { shivering } \\
0-4 \text { scale }\end{array}$ & \multicolumn{2}{|c|}{$0.00[0.00-0.00]$} & \multicolumn{2}{|l|}{$0.00[0.00-4.00]$} & $0.003^{*}$ \\
\hline $\begin{array}{l}\text { PACU nausea } \\
0-6 \text { scale }\end{array}$ & \multicolumn{2}{|c|}{$0.00[0.00-0.00]$} & \multicolumn{2}{|l|}{$0.00[0.00-3.0]$} & $0.008^{*}$ \\
\hline $\begin{array}{l}\text { Satisfaction } \\
0-4 \text { Likert scale }\end{array}$ & \multicolumn{2}{|c|}{$4.0[3.0-4.0]$} & \multicolumn{2}{|l|}{$3.0[1.25-4.0]$} & $<0.001^{*}$ \\
\hline
\end{tabular}




\section{Discussion}

453 To our knowledge, this study is the first performed in Palestine to assess the effects of the

454 5HT3 antagonist ondansetron on the incidence of hypotension and shivering after

455 administration of spinal anesthesia. Ninety women were assessed for eligibility, but 10 were

456 excluded and switched to general anesthesia because spinal anesthesia was contraindicated.

457 The remaining 80 women were enrolled in the study and randomly allocated into two groups:

458 intravenous $4 \mathrm{mg}$ ondansetron or intravenous $0.9 \%$ saline; each treatment was administered

459 prior to spinal anesthesia induction (Fig. 1). There were no demographic differences between

460 the groups $(\mathrm{P}>0.05$; Table 2$)$. Numerous hemodynamic parameters and other observations

461 were recorded every 3 min during the intraoperative period and every 5 min in the PACU.

462

\section{1- The effect of ondansetron on spinal anesthesia-induced shivering}

464 Ondansetron has antishivering effect following both general and spinal anesthesia (Tie et al., 2014). It has a potential advantage in obstetric anesthesia, because of its very low incidence of sedation, hypotension, bradycardia, or risk to the neonate, the mechanism of action of

Ondansetron as antishivering worldwide still not clear and it is proposed to act centrally at the level of the pre-optic anterior hypothalamic region by inhibition of serotonin reuptake and controls there the temperature set point (kelsaka et al., 2006). In our study there was a significant decrease in the incidence and severity of intraoperative shivering in the ondansetron group. This finding is consistent with Tatikonda et al. (2019), an Indian RCT that involved 140 patients was divided into two groups: intravenous ondansetron (4 mg) and placebo ( $0.9 \%$ saline). In that study, the shivering incidence was $17.1 \%$ in the saline group versus $0 \%$ in the ondansetron group $(\mathrm{P}=0.0001)$. The current findings also agree with 
477 Moreover, the results are consistent with an Indian study by Nallam et al. (2017) where they

478 carried out an RCT for 80 participants who underwent $\mathrm{C} / \mathrm{S}$, the shivering incidence in the 8

479 mg ondansetron group was $10 \%$ versus $42.5 \%$ in the $0.9 \%$ saline group $(\mathrm{P}=0.001)$.

480 Furthermore, the results are in agreement with Lie et al. (2016) from China, ondansetron

481 reduced the shivering incidence by $67 \%$. In addition to that, He et al. in 2016 carried out a

482 meta-analysis that used PubMed, Embase, and Cochrane library databases, where total 8

483 RCTs containing 905 subjects were included, the analysis showed that ondansetron

484 effectively decreases spinal anesthesia-induced shivering (He et al., 2016). Finally, Tie et al.

485 (2014) showed a shivering incidence of $49.3 \%$ in the control group and $23.4 \%$ in the

486 ondansetron group.

487 On the contrary, the current study is inconsistent with Shabana et al. (2018). This Egyptian

488 study examined 100 parturient underwent $\mathrm{C} / \mathrm{S}$, found no significant differences regarding

489 shivering incidence: $96 \%$ for the ondansetron group and $100 \%$ for the $0.9 \%$ saline group $(\mathrm{P}=$

490 0.49). Khouly and Meligy (2016), also in Egypt, revealed no significant differences regarding

491 shivering between the two groups: ondansetron (0\%) and placebo (4\%). An Australian RCT

492 of 118 women reported a similar incidence of severe shivering in the ondansetron (32\%) and

$4930.9 \%$ saline (33\%) groups $(\mathrm{P}=0.79$; Browning et al., 2013). Finally, an Indian study reported

494 that ondansetron failed to efficiently manage regional anesthesia-induced shivering, where

$49570.6 \%$ of ondansetron participants complained of shivering (Suresh et al., 2013).

496

497

2- The Effect of Ondansetron on Spinal-anesthesia-induced Hypotension

498 Our results showed a significant decrease in the incidence of intraoperative and postoperative

499 hypotension in the ondansetron group. These results are consistent with Tatikonda et al.

500 (2019), intravenous ondansetron (4 mg) significantly reduced hypotension and ephedrine

501 requirement compared to placebo (0.9\% saline). Boyd (2018) concluded that intravenous 
ondansetron can be used as an additional tool to help prevent spinal anesthesia-induced

503 hypotension.

504 In addition, Shabana et al. (2018) revealed a significantly reduced incidence of hypotension

505 in the ondansetron compared to the control group (30 vs. $70 \%$, respectively) and a significant

506 decrease in vasopressor doses. Badawy and Mokhtar (2017) also reported a lower incidence

507 of spinal anesthesia-induced hypotension in a double-blind RCT. Furthermore, Kholy and

508 Meligyin (2016) reported a significantly lower incidence of hypotension in the ondansetron

509 compared to the control group (30 and 58\%, respectively). In that study, arterial pressure was

510 higher at spinal anesthesia induction and 30 min post- 58 induction $(\mathrm{P}=0.006)$, data that are

511 in agreement with the present study. Gao al. (2015) conducted a meta-analysis and concluded

512 that prophylactic ondansetron can lower the occurrence of both hypotension and vasopressor

513 requirements in spinal anesthesia practice. Lastly, the current study is in line with Trabelsi et

514 al. (2015), in which 80 participants were randomized into two groups (4 mg ondansetron or

$51510 \mathrm{ml}$ of saline). Overall, $37.5 \%$ of patients in the ondansetron group experienced

516 hypotension, compared to $77.5 \%$ in the saline group $(P<0.001)$.

517

518 The current study is inconsistent with several reports regarding the effect of ondansetron on

519 spinal anesthesia-induced hypotension. Choudhary et al. (2019) concluded that intravenous 5-

520 HT3 serotonin receptor antagonist administration prior to spinal anesthesia does not attenuate

521 hemodynamic changes. Moreover, a Thai RCT randomized 228 participants into $0.9 \%$ saline,

$5220.05 \mathrm{mg} / \mathrm{kg}$ ondansetron, or $0.1 \mathrm{mg} / \mathrm{kg}$ ondansetron. There was no difference in hypotension

523 among the groups: saline $=81.9 \%$, ondansetron $(0.05 \mathrm{mg})=84.5 \%$, and ondansetron $(0.1$

$524 \mathrm{mg})=73.6 \%(\mathrm{P}=0.23$; Oofuvong et al., 2018). In addition, Karacaer et al. (2018) found no

525 significant differences in hypotension incidence $(\mathrm{P}=0.76)$. 
526 Terkawi et al. (2016) also presented results that are contradictory to the current findings.

527 They found no differences between the study groups regarding SBP, DBP, MAP, and

528 phenylephrine requirements. The incidence of hypotension was $62 \%$ for the ondansetron

529 group and $61 \%$ for the saline 59 group $(\mathrm{P}=1.00)$. A Spanish RCT conducted to study the

530 efficacy of iv ondansetron on participants hemodynamic during elective caesarean section

531 under spinal anesthesia, concluded that there were no differences in the number of patients with hypotension in the placebo (43.8\%) or $2 \mathrm{mg}(53.1 \%), 4 \mathrm{mg}(56.3 \%)$, and $8 \mathrm{mg}(53.1 \%)$ ondansetron groups $(\mathrm{P}=0.77)$. Furthermore, ephedrine and phenylephrine requirements and

534 the number of patients with adverse effects did not differ among the study groups. In their study, they concluded that prophylactic ondansetron had little effect on the incidence of hypotension in healthy parturient who underwent spinal anesthesia with bupivacaine and fentanyl for elective cesarean delivery (Ortiz-Gomez et al., 2014).

\section{3- The Effect of Ondansetron on Bradycardia}

540 The current study results showed no significant differences regarding the incidence of 541 intraoperative and postoperative bradycardia $(\mathrm{HR}<50 \mathrm{bpm})$. Our results are consistent with several works. Choudhary et al. (2019) concluded that intravenous 5-HT3 serotonin receptor antagonist before spinal anesthesia does not affect HR changes. Tatikonda et al. (2019) found

544 that $5.7 \%$ of patients in the ondansetron group and no patients $(0 \%)$ in the placebo group

545 exhibited bradycardia that required atropine $(\mathrm{P}=0.120)$. In addition, Karacaer et al. (2018)

546 showed no significant differences in the incidence of bradycardia between the study groups.

547 Oofuvong et al. (2018) randomly allocated 228 participants into one of three groups: $0.9 \%$

548 saline, $0.05 \mathrm{mg} / \mathrm{kg}$ ondansetron, or $0.1 \mathrm{mg} / \mathrm{kg}$ ondansetron. The measured HR did not differ 549 among the study groups during the overall operation period. Potdar et al. (2017) conducted a 550 RCT in India with 180 parturient randomly divided into three groups: 0.9\% saline, $4 \mathrm{mg}$ 
ondansetron, and $8 \mathrm{mg}$ ondansetron. HR did not significantly differ among the groups.

Terkawi et al. (2016) also did not find differences between the two groups regarding HR (P =

553 0.18).

554 On the contrary, the current study is inconsistent with several studies. Shabana et al. (2018) reported that ondansetron decreases the occurrence of spinal anesthesia-induced bradycardia.

556 Moreover, a meta-analysis result conducted by Gao et al. (2015) suggested that prophylactic ondansetron reduces the incidence of bradycardia.

\section{4- The Effect of Ondansetron on Pruritus}

560 The present study showed no significant differences regarding the incidence of intraoperative and postoperative pruritus. These findings are consistent with Terkawi et al. (2016). In this study, 86 subjects underwent elective cesarean section, they were randomly allocated, they were anesthetized using a mixture of $15 \mathrm{mg}$ of $0.75 \%$ bupivacaine, $20 \mathrm{mcg}$ of fentanyl, and 100 mcg of preservative-free morphine. The occurrence of pruritus was not statistically different between the ondansetron $(63 \%)$ and placebo $(56 \%)$ groups $(\mathrm{P}=0.59)$. Moreover, the study results are in line with Ortiz-Gomez et al. (2014). This RCT with 128 participantsrandomly divided into placebo or intravenous ondansetron $(2,4$, or $8 \mathrm{mg})$-revealed no statistical differences among the groups regarding pruritus incidence $(\mathrm{P}=0.77)$. Our study is inconsistent with the results of Yeh et al. (2000), in which 60 participants were randomly divided into $0.9 \%$ saline, diphenhydramine, and ondansetron groups. The ondansetron group showed a significantly lower pruritus incidence (25\%) compared to the other groups. They concluded that prophylactic ondansetron can statistically reduce the incidence of pruritus

573 (Yeh et al., 2000). 


\section{5- The Effect of Ondansetron on Pain and Headache}

577 There were no significant differences between the groups regarding the incidence of intraoperative and postoperative pain and headache. The results are consistent with Yeh et al.

579 (2000), where 60 participants were randomly divided into $0.9 \%$ saline, diphenhydramine, and 580 ondansetron groups. The postoperative pain score and headache among all study groups did 581 not statistically differ in that study.

\section{Recommendations}

584 In clinical practice, it is recommended to administer $4 \mathrm{mg}$ ondansetron intravenously prior to spinal anesthesia induction for women who will undergo a cesarean section. This administration should attenuate the incidence of spinal anesthesia-induced shivering and hypotension. Furthermore, ondansetron is a category A drug and is thus safe to use during pregnancy. It also has well-known antiemetic and anti-nausea effects. Larger sample sizes are required to detect the exact effectiveness of ondansetron on the attenuation of spinal anesthesia-induced shivering and hypotension in women who undergo a cesarean section.

\section{Conclusions}

593 In the current study, $4 \mathrm{mg}$ ondansetron administration in parturient who underwent elective

594 cesarean section significantly and effectively decreased intraoperative and postoperative

595 spinal anesthesia-induced hypotension and vasopressor use, reduced intraoperative and

596 postoperative spinal anesthesia-induced shivering (incidence and severity) and meperidine

597 use, decreased intraoperative nausea (severity), postoperative nausea (incidence and severity), postoperative vomiting, and intraoperative and postoperative dizziness compared to

599 saline. On the other hand, ondansetron was not effective in the prevention of the following:

600 intraoperative and postoperative bradycardia, intraoperative and postoperative headache, 
601

602

603

604

605

606

607

608

609

610

611

612

613 intraoperative and postoperative pain (incidence and intensity), intraoperative and

postoperative pruritus, intraoperative nausea (incidence), intraoperative vomiting and

intraoperative and postoperative respiratory depression. Finally, the participant's satisfaction rating was higher in the ondansetron group compared to the control group.

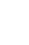

\section{References}

1. Asahq.org. (2020). American Society of Anesthesiologists (ASA). [online] Available at: https://www.asahq.org/ [Accessed 8 Feb. 2020].

2. Bay, J., Nunn, J., \& Prys-Roberts, C. (1968). Factors influencing arterial PO2 during recovery from anaesthesia. BJA: British Journal of Anaesthesia, 40(6), 398-407.

3. Begum, R., Islam, R., Sarker, P. C., Karmakar, K. K., \& Alam, A. M. (2008). Prophylactic use of ketamine hydrochloride for prevention of postoperative shivering. Journal of BSA, 21(1), 29-35.

4. Boonstra, A., Stewart, R., Köke, A., Oosterwijk, R., Swaan, J., Schreurs, K. and Schiphorst Preuper, H., 2016. Cut-Off Points for Mild, Moderate, and Severe Pain on the Numeric Rating Scale for Pain in Patients with Chronic Musculoskeletal Pain: Variability and Influence of Sex and Catastrophizing. Frontiers in Psychology, 7. 
621

622

623

624

625

626

627

628

629

630

631

632

633

634

635

636

637

638

5. Ferreira-Valente, M. A., Pais-Ribeiro, J. L., \& Jensen, M. P. (2011). Validity of four pain intensity rating scales. Pain, 152(10), 2399-2404. doi: 10.1016/j.pain.2011.07.005

6. Ghani, N., Varshney, A., Hasan, M., Jamil, S. N., \& Sinha, A. Spinal Anaesthesia or General Anaesthesia? Which is better in Premature Neonates: A Case Report.

7. Giesbrecht, G. G., Sessler, D. I., Mekjavic, I. B., Schroeder, M., \& Bristow, G. K. (1994). Treatment of mild immersion hypothermia by direct body-tobody contact. Journal of Applied Physiology, 76(6), 2373-2379.

8. Halpin, A., Huckabay, L., Kozuki, J. and Forsythe, D., 2010. Weigh the benefits of using a 0-to-5 nausea scale. Nursing, 40(11), pp.18-20.

9. He, K., Zhao, H., \& Zhou, H. (2016). Efficiency and safety of ondansetron in preventing postanaesthesia shivering. The Annals of The Royal College of Surgeons of England, 98(6), 358-366.

10.Kelsaka, E., Baris, S., Karakaya, D., \& Sarhasan, B. (2006). Comparison of Ondansetron and Meperidine for Prevention of Shivering in Patients Undergoing Spinal Anesthesia. Regional Anesthesia and Pain Medicine, 31(1), 40-45. doi: 10.1097/00115550-200601000-00008 
639 11.Kim, H. Y., Lee, K. C., Lee, M. J., Kim, M.-N., Kim, J.-S., Lee, W. S., \&

640 Lee, J. H. (2014). Comparison of the efficacy of a forced-air warming 641 system and circulating-water mattress on core temperature and post642 anesthesia shivering in elderly patients undergoing total knee arthroplasty 643 under spinal anesthesia. Korean journal of anesthesiology, 66(5), 352644357.

645 12.Langesæter, E., Rosseland, L. A., \& Stubhaug, A. (2008). Continuous $646 \quad$ Invasive Blood Pressure and Cardiac Output Monitoring during Cesarean 647 DeliveryA Randomized, Double-blind Comparison of Low-dose 648 versusHigh-dose Spinal Anesthesia with Intravenous Phenylephrine or Placebo Infusion. Anesthesiology: The Journal of the American Society of Anesthesiologists, 109(5), 856-863.

651 13.Lee, Jennifer E., Ronald B. George, and Ashraf S. Habib. 2017. "Spinal652 Induced Hypotension: Incidence, Mechanisms, Prophylaxis, and 653 Management: Summarizing 20 Years of Research.” Best Practice \& 654 $\begin{array}{lllll}\text { Research } & \text { Clinical Anaesthesiology } & 31 & \text { (1): } & \text { 57-68. }\end{array}$ https://doi.org/10.1016/j.bpa.2017.01.001.

656 14.Limongi, J. A. G., \& Lins, R. S. A. d. M. (2011). Cardiopulmonary arrest in spinal anesthesia. Revista brasileira de anestesiologia, 61(1), 115-120. 
15.Macintyre, P. E., Pavlin, E. G., \& Dwersteg, J. F. (1987). Effect of meperidine on oxygen consumption, carbon dioxide production, and respiratory gas exchange in postanesthesia shivering. Anesthesia and analgesia, 66(8), 751-755.

16.Nallam, S., Cherukuru, K., \& Sateesh, G. (2017). Efficacy of intravenous ondansetron for prevention of postspinal shivering during lower segment cesarean section: A double-blinded randomized trial. Anesthesia: Essays and Researches, 11(2), 508-513. doi:10.4103/aer.AER_26_17

17.Oofuvong, M., Kunapaisal, T., Karnjanawanichkul, O., Dilokrattanaphijit, N., \& Leeratiwong, J. (2018). Minimal effective weight-based dosing of ondansetron to reduce hypotension in cesarean section under spinal anesthesia: a randomized controlled superiority trial. BMC Anesthesiology, 18(1), 105.

18.Ortiz-Gómez, J., Palacio-Abizanda, F., Morillas-Ramirez, F., Fornet-Ruiz, I., Lorenzo-Jiménez, A., \& Bermejo-Albares, M. (2014). The effect of intravenous ondansetron on maternal haemodynamics during elective caesarean delivery under spinal anaesthesia: a double-blind, randomised, placebo-controlled trial. International journal of obstetric anesthesia, 23(2), 138-143. 
678 19.Reynolds, L., Beckmann, J., \& Kurz, A. (2008). Perioperative complications 679 of hypothermia. Best practice \& research Clinical anaesthesiology, 22(4), $680 \quad 645-657$.

681 20.Shabana, A., Elkholy, N., Mohamed, A., \& Abdel Hamid, M. (2018). Effect 682 of ondansetron on hypotension and bradycardia associated with spinal 683 684 anesthesia during cesarean section. Menoufia Medical Journal, 31(1), 1217. doi:10.4103/1110-2098.234215

21.Suresh, J. S., Arora, A., George, A., \& Vinayak, S. R. (2013). Comparison of intravenous butorphanol, ondansetron and tramadol for control of shivering during regional anesthesia: A prospective, randomized double-blind study. Anaesthesia, Pain \& Intensive Care, 17(1).

22.Tsai, Y.-C., \& Chu, K.-S. (2001). A comparison of tramadol, amitriptyline, and meperidine for postepidural anesthetic shivering in parturients. Anesthesia \& Analgesia, 93(5), 1288-1292.

23.Warltier, D. C., Campagna, J. A., \& Carter, C. (2003). Clinical relevance of the Bezold-Jarisch reflex. Anesthesiology: The Journal of the American Society of Anesthesiologists, 98(5), 1250-1260. 


\section{Enrolment}

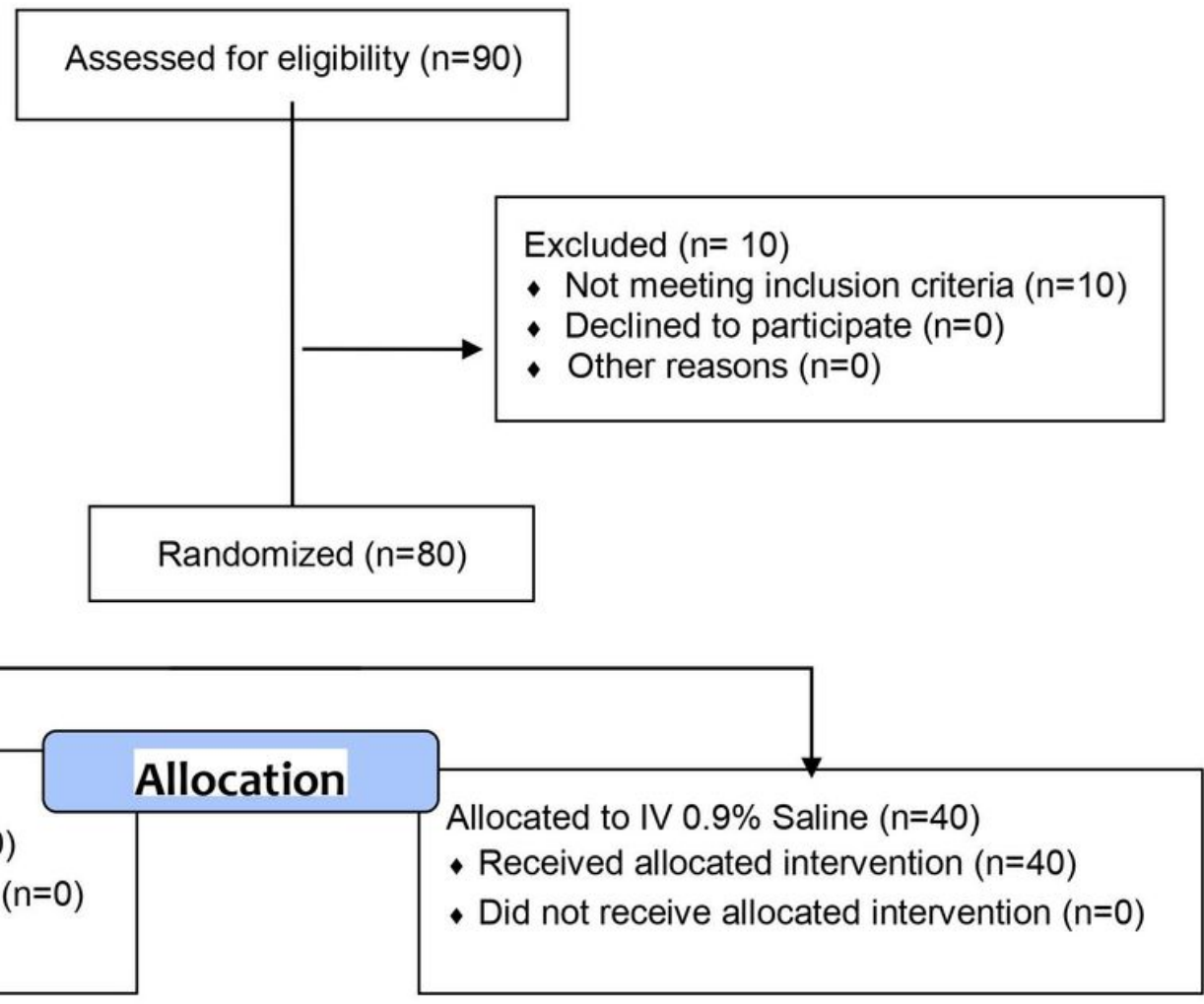

Allocated to IV Ondansetron $(n=40)$

- Received allocated intervention $(n=40)$

- Did not receive allocated intervention $(n=0)$

- Received allocated intervention $(n=40)$

- Did not receive allocated intervention $(n=0)$

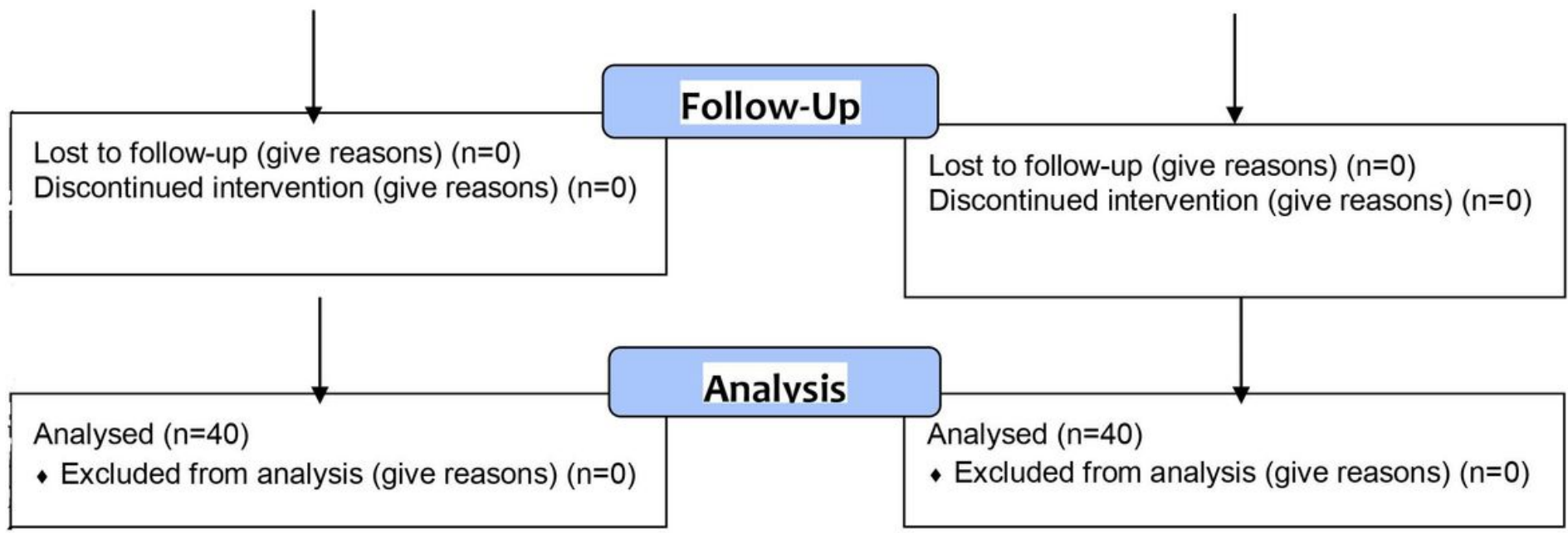

\section{Figure 1}

